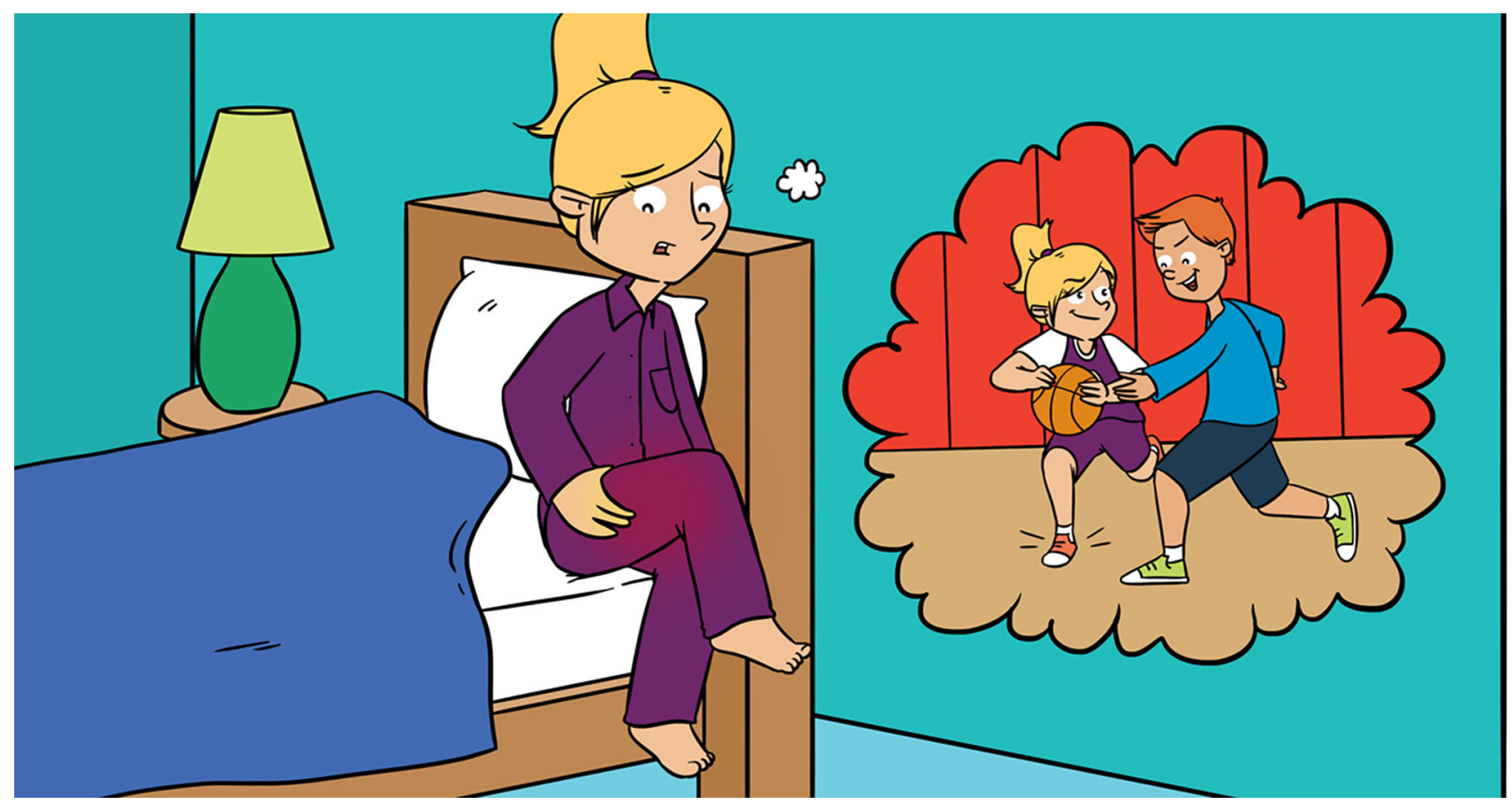

\title{
ECCENTRIC EXERCISE IS POWERFUL BUT CAN BE PAINFUL
}

\author{
Pierre Clos $^{1 *}$, Yoann M. Garnier ${ }^{2+}$ and Romuald Lepers ${ }^{1+}$ \\ 1 INSERM UMR1093-CAPS, UFR des Sciences du Sport, Université Bourgogne Franche-Comté, Dijon, France \\ ${ }^{2}$ UFR des Sciences du Sport, AME2P, Université Clermont-Auvergne, Clermont-Ferrand, France
}

YOUNG REVIEWERS:

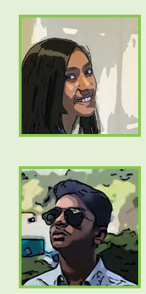

NITYA

AGE: 10

SIDHAARTH

AGE: 14
Your muscles can contract in different ways: when you walk upstairs, the muscles at the fronts of your thighs shorten (concentric contraction), whereas when you walk downstairs, they lengthen (eccentric contraction). Concentric contractions require more oxygen and thus make you burn more calories. Eccentric contractions are easier but break parts of the muscle and make you feel sore for several days. If you repeat eccentric exercises, however, your muscles will probably get bigger and stronger than they would by repeating concentric contractions. Most physical activities (like running and jumping) include both concentric and eccentric phases. Scientists have designed tools to study each type of muscle contraction, such as eccentric cycling, which uses a bike on which you must resist the pedals as they are driven backward by an engine. 
Figure 1

Concentric and eccentric phases of two movements. (A) When squatting, concentric contraction occurs in the quadriceps when you move upwards and the quadriceps shorten Eccentric contraction happens when you move downwards and the quadriceps lengthen. (B) In arm flexion, the elbow flexor muscles shorten in the concentric phase when the hand is moved toward the body, and lengthen in the eccentric phase when the hand is moved away. In the eccentric phase, the elbow flexor muscle stretches. The blue and red arrows show the direction of body movement while the white arrows show the direction of muscle contraction.

\section{CONCENTRIC CONTRACTION}

The muscle shortens to produce force.

\section{QUADRICEPS}

The muscles at the front of the thigh that make the knee straighten when they contract, raising the foot if you are sitting.

\section{ECCENTRIC CONTRACTION}

The muscle stretches and resists at the same time, and thus produces force while lengthening.
A

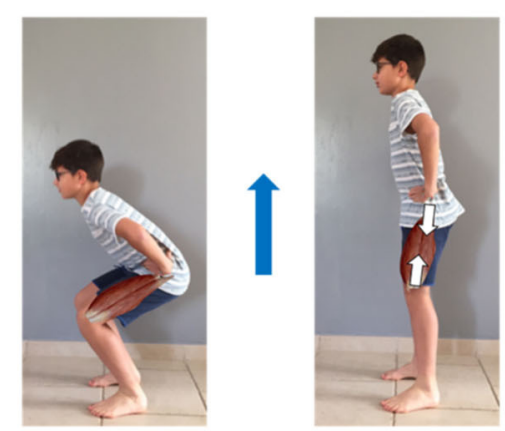

B

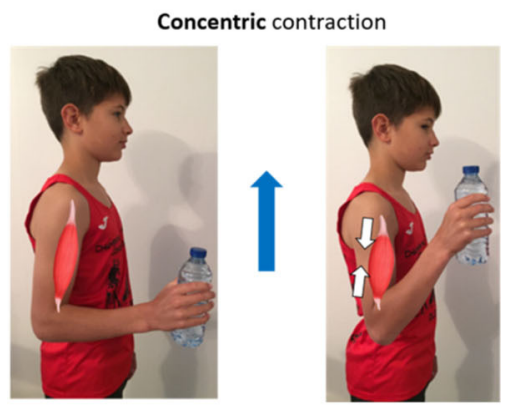

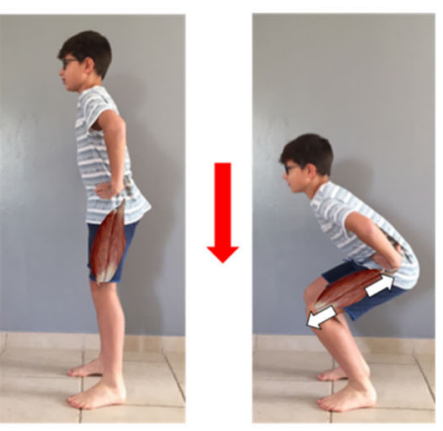

Eccentric contraction

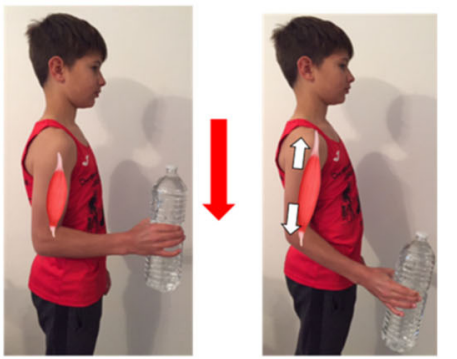

Figure 1

\section{INTRODUCTION}

Do you have any idea why it is easier to walk downstairs than upstairs? Part of the explanation lies in the fact that your leg muscles, which help you move, contract in different ways depending on the exercise. Stepping upstairs involves what are called concentric muscle contractions, meaning your leg muscles (quadriceps in this case) shorten when you step up. Walking downstairs involves eccentric contractions, during which your quadriceps muscles stretch. Here is another example: imagine you dropped your pen and squat to grab it. In this case, your quadriceps muscles lengthen while you squat down (eccentric contraction) and shorten (concentric contraction) when you get back up (Figure 1).

Concentric exercises make you breathe more heavily, but your muscles recover quickly once you are done. On the other hand, eccentric contractions feel easier but break parts of your muscles, sometimes causing pain for a couple of days.

\section{HOW DO YOUR MUSCLES MAKE YOU MOVE?}

To understand the two types of movement, we must look inside the muscle (Figure 2). A muscle is made of fibers that look like tubes running parallel to each other. In each fiber, there are even smaller units arranged end-to-end, called sarcomeres. On the very ends of each muscle are tendons, which are attached to bones. When your muscles contract concentrically (such as your quadriceps 
Figure 2

The main components of a muscle. The tendon connects the muscle to the bone. The muscle is made of smaller units called fibers, in which we find sarcomeres.

\section{MUSCLE FIBERS}

Tube-shaped structures that make up muscles. There can be hundreds of thousands of fibers per muscle. They extend from one end of the muscle to the other.

\section{SARCOMERES}

Small units that line up end-to-end to make up muscle fibers. When sarcomeres contract. the muscle fibers contract. Sarcomeres can break when overstressed, causing muscle soreness.

\section{TENDONS}

Structures that connect bones and muscles.

\section{DELAYED ONSET OF} MUSCLE SORENESS

You muscles start to be sore a day after having performed eccentric contractions and this often lasts a few days.

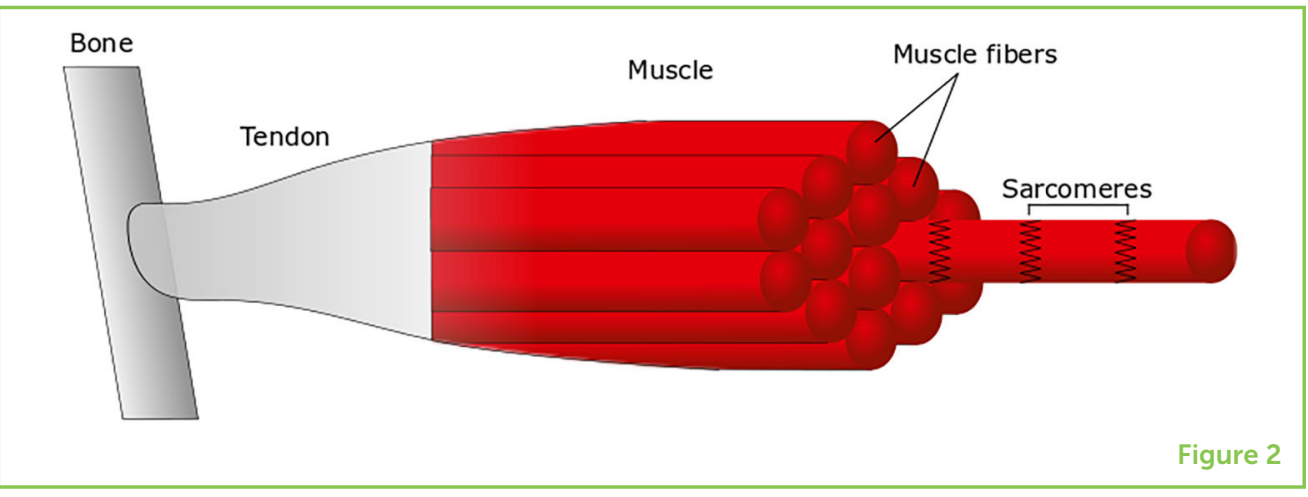

when pedaling your bike), sarcomeres shorten and together pull one bone toward the other as the joint bends (for instance your elbow joint when your arm comes toward your shoulder, as in Figure 1B). When you perform eccentric contractions, such as when you slow down to a stop after running, your muscles lengthen and contract simultaneously in order to resist your body weight, which is a force pushing you forward while you are trying to stop. In these situations, part of the strength is produced without effort by your tendons, while during concentric contractions your sarcomeres do all the work. Consequently, concentric contractions require more energy [1].

\section{WHY DO YOUR MUSCLES GET SORE AFTER SOME EXERCISES?}

Have your ever spent a whole afternoon playing outside and felt fine right after, but the next day your legs felt sore? This is called delayed onset of muscle soreness [2]. It occurs when you exercise too hard or in a way you are not used to. If you overstress your muscles, your sarcomeres break, and you lose strength. The harder you exercise, the more sore you will be. The pain is due to bodily processes that help rebuild damaged muscle fibers, and it lets you know that you need to rest [2]. So, you should not see this pain as a foe, but be glad of the advice it gives you-allow your muscles to recover so that they get stronger. The point of this muscle-rebuilding process is to be able to repeat the same exercise with less pain and tiredness.

\section{ECCENTRIC EXERCISES CAUSE THE GREATEST SORENESS}

During most physical activities, your muscles need to contract both concentrically and eccentrically. For instance, when you run, the quadriceps of the leg that is touching the ground shorten when pushing forwards and upwards (concentric phase), and the quadriceps of the other leg lengthen as you land on your other foot (eccentric phase), then shorten again, making you bounce upwards and forwards, and so on. 
As mentioned, when the sarcomeres within your muscle fibers are broken, delayed onset of muscle soreness appears within $24 \mathrm{~h}$ and lasts up to 3-4 days after the exercise. Soreness is much more likely to occur after performing many eccentric contractions, because in the eccentric phase your muscles stretch. Examples of movements that include a lot of eccentric contraction are running downhill, changing direction to dodge an opponent in football, or landing from a jump in basketball.

The stronger the eccentric contraction, the larger the number of muscle fibers to repair, the greater the soreness, and the stronger the muscle is rebuilt. Scientific studies also showed that the further you stretch your muscles, the more muscle fibers are broken. This happens, for example, when the knee on the side of your foot touching the ground bends a lot [3]. This means that you can preserve your muscles when running by taking shorter, quicker strides; and this is especially true when running downhill.

Any eccentric exercise will help protect the muscles against damage resulting from the next eccentric exercise session, after which you will be less tired and sore [2].

\section{DO ECCENTRIC EXERCISES MAKE YOU STRONGER?}

If you train several times a week for a month or more, you will notice improvements in the qualities you have been working on. For instance, if you do weight training, you will gain strength and you may sprint faster, yet you might not be able to run for longer.

Scientists studied concentric and eccentric contractions separately, using devices on which you can either push (concentric) or resist (eccentric), and then rest as the device carries your limb back to its starting position. Eccentric contractions can increase muscle strength more than concentric contractions, for two main reasons [4]. First, as your muscles get bigger, their fibers are split into a greater number of sarcomeres, which increases the overall strength of the muscle. Second, the tendons get stiffer when performing eccentric but not concentric training, more efficiently transmitting the force from the muscles to the bones. To understand why stiff tendons are helpful, imagine that your parents' car broke down and you have to pull it to the mechanic, a block away. Would you rather use a stiff rope or an elastic? It will be easier with a stiff rope!

Eccentric contraction also uses less energy than concentric contraction. Because oxygen carries energy to your muscles, it not surprising that researchers found that you use less oxygen walking downhill than uphill on a treadmill at the same pace [5], and you breathe less heavily. You might begin to think that concentric contractions are too much effort, yet if you repeat those exercises over 
Figure 3

Eccentric cycling. The blue cyclist pushes on the pedals (concentric contraction of knee extensor muscles), pulling the chain and the pedals of the red cyclist, who resists to slow his/her partner down (eccentric contraction of knee extensor muscles). It is much easier for the red cyclist to resist than for the blue cyclist to push The blue cyclist will breathe less heavily and expend less energy.

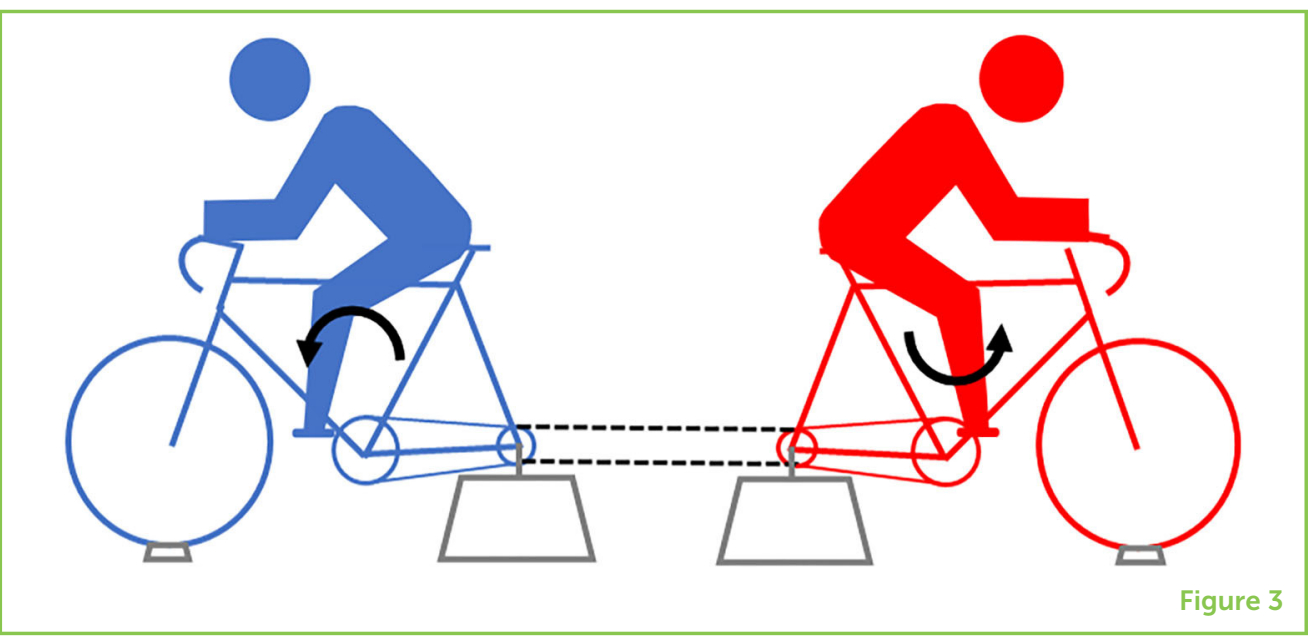

several weeks, you will be able to use more oxygen [6] and improve your endurance.

Concentric exercise burns more calories while you are doing it, but even though it feels like less work while you are exercising, eccentric exercise burns more calories in the hours and days following the exercise. So, the overall number of calories you burn from each type of exercise balances out [7]. Eccentric exercise burns calories later because your body must expend energy to repair your muscles. Moreover, bigger muscles need to be fed more. As more of the energy you get from food is used to repair your muscles and keep them in shape, less energy will be stored as fat. More muscle and less fat: it is a win-win situation.

Since most sports include both types of muscle contraction, it is difficult to say which type of contraction primarily gives us the results of the exercise or influences how hard it feels. Cycling, however, totally consists of concentric contractions. This gave researchers the idea of creating a bike that does the opposite-eccentric cycling (Figure 3). They attached two bikes back-to-back, with a single chain so that when the strongest cyclist pushed on the pedals (concentric), the other could only resist and pedal backwards (eccentric). Today, eccentric cycling functions with an engine driving the pedals, and this exercise modality is used in rehabilitation programs. Patients find it very easy and report low levels of muscle soreness [8].

\section{CONCLUSION}

Concentric and eccentric muscle contractions are present in most physical activities during different phases of the movement. Eccentric contractions participate more in improving strength and burning calories afterward, when you are at rest, and they are largely responsible for delayed onset of muscle soreness. The concentric phase uses most of the energy needed during the exercise and burns 
the most calories while you are exercising. Due to their complimentary benefits, it is recommended that we do exercises consisting of both types of contractions. Thankfully, this is the case for most physical activities. The time you give to eccentric vs. concentric exercise will depend on what you train for. For instance, if you are a road cyclist, you will need to do little eccentric exercise, such as repeated jumps. Jumping is a good way of strengthening muscles and tendons though, and kids should do jumping exercises regularly, yet cautiously, while growing up.

It is good to remember that the pain resulting from eccentric contractions is necessary for your muscles to get stronger. The degree of soreness you feel and the amount of strength or muscle mass you gain are not only a matter of how hard you exercise, but of how much you stretch your muscles as well. Furthermore, you must listen to pain because it is an alarm telling you it is time to rest. Being sore the days following the exercise is what it takes to get stronger; as the saying goes "no pain no gain."

\section{ACKNOWLEDGMENTS}

We thank Pr. Sandra Hunter and her daughter Kennedy for their mindful feedback on the manuscript.

\section{REFERENCES}

1. Morgan, D. L. 1990. New insights into the behavior of muscle during active lengthening. Biophys. J. 57:209-21. doi: 10.1016/S0006-3495(90)82524-8

2. Hyldahl, R. D., Chen, T. C., and Nosaka, K. 2017. Mechanisms and mediators of the skeletal muscle repeated bout effect. Exerc. Sport Sci. Rev. 45:24-33. doi: 10.1249/JES.0000000000000095

3. Lieber, R. L., and Friden, J. 1993. Muscle damage is not a function of muscle force but active muscle strain. J. Appl. Physiol. 74:520-6. doi: 10.1152/ jappl.1993.74.2.520

4. Douglas, J., Pearson, S., Ross, A., and McGuigan, M. 2017. Chronic adaptations to eccentric training: a systematic review. Sports Med. 47:917-41. doi: 10.1007/ s40279-016-0628-4

5. Lemire, M., Lonsdorfer-Wolf, E., Isner-Horobeti, M. E., Kouassi, B. Y. L., Geny, B., Favret, F., et al. 2018. Cardiorespiratory responses to downhill versus uphill running in endurance athletes. Res. Q. Exerc. Sport 89:511-7. doi: 10.1080/ 02701367.2018.1510172

6. Lewis, M. C., Peoples, G. E., Groeller, H., and Brown, M. A. 2018. Eccentric cycling emphasising a low cardiopulmonary demand increases leg strength equivalent to workload matched concentric cycling in middle age sedentary males. J. Sci. Med. Sport 21:1238-43. doi: 10.1016/j.jsams.2018.05.009

7. Peñailillo, L., Blazevich, A., and Nosaka, K. 2014. Energy expenditure and substrate oxidation during and after eccentric cycling. Eur. J. Appl. Physiol. 114:805-14. doi: 10.1007/s00421-013-2816-3 
8. Clos, P., Laroche, D., Stapley, P. J., and Lepers, R. 2019. Neuromuscular and perceptual responses to sub-maximal eccentric cycling. Front. Physiol. 10:354. doi: 10.3389/fphys.2019.00354

SUBMITTED: 27 May 2020; ACCEPTED: 22 December 2020;

PUBLISHED ONLINE: 01 February 2021

EDITED BY: Jorge Galindo-Villegas, Nord University, Norway

CITATION: Clos P, Garnier YM and Lepers R (2021) Eccentric Exercise Is Powerful but Can Be Painful. Front. Young Minds 8:566235. doi: 10.3389/frym.2020.566235

CONFLICT OF INTEREST: The authors declare that the research was conducted in the absence of any commercial or financial relationships that could be construed as a potential conflict of interest.

COPYRIGHT @ 2021 Clos, Garnier and Lepers. This is an open-access article distributed under the terms of the Creative Commons Attribution License (CC BY). The use, distribution or reproduction in other forums is permitted, provided the original author(s) and the copyright owner(s) are credited and that the original publication in this journal is cited, in accordance with accepted academic practice. No use, distribution or reproduction is permitted which does not comply with these terms.

\section{YOUNG REVIEWERS}
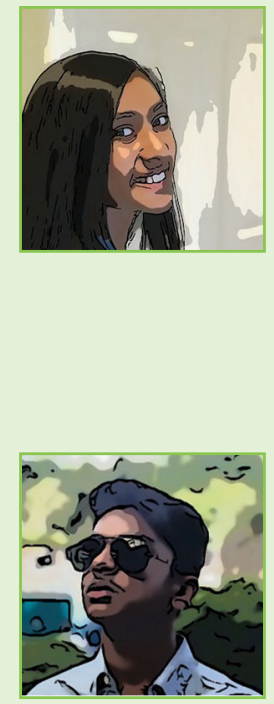

\section{NITYA, AGE: 10}

I love to experiment and try new things in art, crafts, science, and technology. My favorite pastime is to do crafts and TikTok's. My favorite subjects in school are math and science. I like science the most because it teaches me learn how things work. Basketball is my favorite sport. I would like to be a young reviewer to learn more about how science helps us understand things around us, especially the human body. I like music and can play instruments, such as piano and saxophone. I am also learning Indian classical vocal music.

\section{SIDHAARTH, AGE: 14}

My favorite subjects in school are math and science. I like biology the most because I enjoy dissections, they give me a hands-on experience to understand the different functions of the body. I like playing basketball and baseball. This opportunity is interesting to me because it will help me to understand different perspectives on many topics in the world. I also like music and can play instruments, such as guitar and saxophone. I am also learning Indian classical vocal music.

\section{AUTHORS}

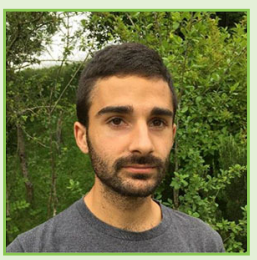

\section{PIERRE CLOS}

I am a Ph.D. student at the University of Bourgogne, France. I study how people feel when they do eccentric cycling and try to figure how it affects the way 

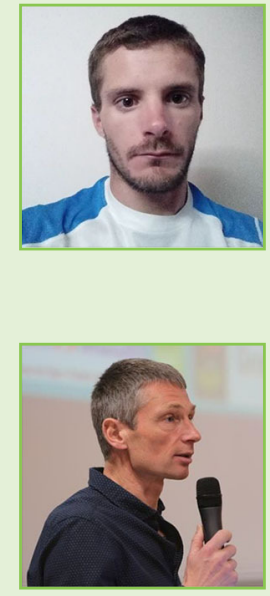

their brain commands their muscles, and how it tires their muscles. I compare eccentric cycling to standard, concentric cycling. During my spare time, I enjoy running on trails or reading all kinds of books. *pierre.clos@u-bourgogne.fr; torcid.org/0000-0002-9435-9991

\section{YOANN M. GARNIER}

I am Associate Professor in exercise physiology at the Faculty of Sport Sciences of Clermont-Ferrand in France. My research interest focuses on the effect of eccentric mode of muscle contraction on nerve pathways and muscle function, to optimize its use for training or rehabilitation purposes. I like practicing outdoor activities, such as running, mountain biking, or kayaking. ${ }^{\dagger}$ orcid.org/0000-0001-5778-4684

\section{ROMUALD LEPERS}

I am a Professor in exercise physiology at the Faculty of Sport Sciences of Dijon, University of Bourgogne (France). My laboratory is part of the National Institute for Health and Medical Research (INSERM CAPS). I am interested in how physical exercise affects muscular and neural systems. I also perform research on age-related change in endurance performance. Outside of work, I love swimming, cycling, running, and taking part in triathlon races. ${ }^{\dagger}$ orcid.org/0000-0002-3870-4017 